\title{
EVALUATION OF GENOTYPIC DIVERSITY OF Streptococcus mutans USING DISTINCT ARBITRARY PRIMERS
}

\author{
Cínthia Pereira Machado TABCHOURY ${ }^{1}$, Maria Clara K. SOUSA ${ }^{2}$, Rodrigo Alex ARTHUR ${ }^{3}$, \\ Renata Oliveira MATTOS-GRANER ${ }^{4}$, Altair Antoninha DEL BEL CURY ${ }^{5}$, Jaime Aparecido CURY ${ }^{6}$
}

\author{
1- Pharm D, MSc, PhD, Associate Professor, Department of Physiological Science, Dental School of Piracicaba, State University of Campinas, \\ Piracicaba, SP, Brazil. \\ 2- Undergraduate student, Department of Physiological Science, Dental School of Piracicaba, State University of Campinas, Piracicaba, SP, Brazil. \\ 3- DDS, MSc, Graduate student, Department of Physiological Science, Dental School of Piracicaba, State University of Campinas, Piracicaba, SP, \\ Brazil. \\ 4- DDS, MSc, PhD, Department of Oral Diagnosis, Dental School of Piracicaba, State University of Campinas, Piracicaba, SP, Brazil. \\ 5- DDS, MSc, PhD, Full Professor, Department of Prosthodontics and Periodontology, Dental School of Piracicaba, State University of Campinas, \\ Piracicaba, SP, Brazil. \\ 6- DDS, MSc, PhD, Full Professor, Department of Physiological Sciences, Dental School of Piracicaba, State University of Campinas, Piracicaba, SP, \\ Brazil.
}

Corresponding address: Dra. Cínthia Pereira Machado Tabchoury - Av. Limeira, 901, 13414-903 Piracicaba, SP, Brasil.

Phone: +55-19-2106-5304. Fax: +55-19-2106-5212. E-mail: cinthia@fop.unicamp.br

Received: April 08, 2008 - Modification: - - Accepted: June 25, 2008

\begin{abstract}
S

treptococcus mutans has been considered one of the main etiological agents of dental caries and the genotypic diversity rather than its salivary counts may be considered as a virulence factor of this bacterium. For genotyping with polymerase chain reaction (PCR) with arbitrary primers, several primers have been used in order to improve complexity and specificity of amplicon patterns. Thus, the aim of this study was to evaluate the degree of agreement of genotypic identification among AP-PCR reactions performed with 5 distinct arbitrary primers of $S$. mutans isolated from saliva. Stimulated saliva was collected from 11 adult volunteers for isolation of $S$. mutans, and a total of 88 isolates were genotyped with arbitrary primers OPA 02, 03, 05, 13 and 18 . Fourteen distinct genotypes were identified in the saliva samples. Most volunteers (9 out of 11) presented only one genotype. The results of the present study suggest that primers OPA $02,03,05$ and 13 were suitable for genotypic identification of $S$. mutans isolates of saliva from adult volunteers.
\end{abstract}

Key words: AP-PCR. Arbitrary primers. Genotypes. Saliva. Streptococcus mutans.

\section{INTRODUCTION}

Dental caries is a multifactorial infectious disease, related to biofilm accumulation on dental surface ${ }^{16}$ and frequent consumption of fermentable carbohydrates ${ }^{2}$. By the fermentation of dietary carbohydrates, the bacteria in the dental biofilm produce acids that decrease the $\mathrm{pH}$ and increase the biofilm potential in promoting dental demineralization ${ }^{3,4}$. Additionally, the acid environment selects cariogenic bacteria, such as mutans streptococci ${ }^{16}$. Among them, Streptococcus mutans is known to be one of the most important cariogenic microorganisms ${ }^{15,16}$ because, in addition to being acidogenic and acid-tolerant, it uses sucrose to produce insoluble glucans in biofilm matrix ${ }^{3}$, which may play an important role in the development of caries $^{3,5,17,22}$. Different genotypes of $S$. mutans may present different expression levels of glucosyltransferases ${ }^{19}$ and higher production of insoluble polysaccharides has been reported by genotypes from caries-active individuals ${ }^{8,20}$.

Different genotypes of $S$. mutans have been found in saliva, and dental biofilm and AP-PCR technique has been widely used to discriminate this genotypic diversity ${ }^{1,6,7,9,11,12,18,23,26}$. This technique has a discriminatory potential comparable to other techniques for genotypic identification of $S$. mutans $s^{13,14,28}$. However, different arbitrary primers have been used for $S$. mutans genotyping. The application of more than one arbitrary primer was suggested to increase the discriminatory power of AP-PCR genotyping ${ }^{13,29}$. Saarela, et al. ${ }^{28}$ (1996) have reported that primers OPA 05 and OPA 13 were efficient to identify $S$. mutans genotypes. Truong, et al. ${ }^{29}$ (2000), investigating genotypic diversity among mutans streptococci, verified that 
primers OPA 03 and OPA 18 were capable to distinguish $S$. mutans from other oral microorganisms. Li and Caufield ${ }^{13}$ (1998), after evaluating various arbitrary primers in the genotyping of reference strains of $S$. mutans, suggested that the primer OPA 02 showed the best power of genotype discrimination, giving the highest number of amplicons when compared to other primers. OPA 02 has been recently widely adopted in AP-PCR protocols ${ }^{1,9,12,18,20,23}$. Nevertheless, there is always the question whether other primers should be used to ascertain this diversity and, in addition, the evaluation of different primers was performed with only reference strains ${ }^{13}$.

Thus, the aim of the present study was to evaluate the degree of agreement of genotypic identification between APPCR reactions performed with distinct arbitrary primers (OPA 02, OPA 03, OPA 05, OPA 13 and OPA 18) of Streptococcus mutans isolated from saliva of adult volunteers.

\section{MATERIAL AND METHODS}

\section{Streptococcus mutans Isolates}

This research was approved by the Research Ethics Committee of the Dental School of Piracicaba, State University of Campinas (Protocol \#078/2007), the volunteers were fully informed about the procedures, and written consent was obtained prior to the beginning of the study. Stimulated saliva from 11 volunteers, who participated in a previous study evaluating the effect of sucrose on genotypic diversity ${ }^{1}$, was collected for isolation of mutans streptococci. Healthy volunteers (18 to 28 years old), who fulfilled inclusion criteria (counts of mutans streptococci in saliva from $10^{3}$ to $10^{6}$ colony-forming units (cfu) per $\mathrm{mL}$ ) and exclusion criteria (antibiotic use for the last 2 months prior to the beginning of the study, use of any form of medication that modifies salivary secretion, periodontal disease, general/systemic diseases) took part in this study. $S$. mutans morphological types were isolated, and DNA from these colonies was extracted ${ }^{1,18}$. Thereafter, PCR with specific primers ( $g t f \mathrm{~B}$ and $g b p \mathrm{~B})$ was conducted ${ }^{18,24}$ for identification of $S$. mutans, and then, these isolates were submitted to genotyping protocols by arbitrarily primed polymerase chain reaction (AP-PCR) with 5 different arbitrary primers: OPA 02 , OPA 03 , OPA 05 , OPA 13 and OPA 18.

\section{S. mutans Isolation and Identification}

Stimulated saliva samples were collected by parafilm chewing, in the morning, under fasting condition, and without previous toothbrushing. Saliva samples were diluted in sterile $0.9 \% \mathrm{NaCl}$ and plated on mitis salivarius-bacitracin agar (MSB) (Difco, Sparks, MD, USA). After incubation for $48 \mathrm{~h}$ at $37^{\circ} \mathrm{C}$ in $10 \% \mathrm{CO}_{2}, 8$ representative morphological types of $S$. mutans colonies were collected from each sample, subcultured on mitis salivarius agar (MSA) (Difco, Sparks, $\mathrm{MD}, \mathrm{USA})$ and pure cultures stored at $-70^{\circ} \mathrm{C}$ in $10 \%$ skim milk medium ${ }^{10}$. The purity and identity of the isolates were checked by Gram's stain and colonial morphology on MSA.
Then, aliquots were collected from skim milk and plated on Brain Heart Infusion (BHI) (Difco, Sparks, MD, USA), which was incubated for $24 \mathrm{~h}$ at $37^{\circ} \mathrm{C}$ in $10 \% \mathrm{CO}_{2}$. The colonies from BHI agar were inoculated into Todd Hewitt Broth (Difco, Sparks, MD, USA) and incubated for $18 \mathrm{~h}$ at $37^{\circ} \mathrm{C}$ and $10 \% \mathrm{CO}_{2}$. Cultures were then centrifuged at $4^{\circ} \mathrm{C}$ for $15 \mathrm{~min}$, genomic DNA was extracted and purified from cell pellet ${ }^{18}$, and stored at $-20^{\circ} \mathrm{C}$. Integrities of the genomic DNA samples were checked in samples electrophoretically resolved in $1 \%$ agarose gel and stained with ethidium bromide $(5 \mu \mathrm{g} / \mathrm{mL})$. Isolates were confirmed for species identity in PCR reactions with primers specific for $g t f B$, enconding glucosyltransferase B (5'ACTACACTTTCGGGTGGCTTGG-3' and 5' CAGTATAAGCGCCAGTTTCATC-3' ' $)^{24}$, and specific to $g b p \mathrm{~B}$, enconding glucan-binding protein $\mathrm{B}\left(5^{\prime}\right.$ CAACAGAAGCACAACCATCA-3, and 5' TGTCCACCATTACCCCAGT-3' ${ }^{18}$. Although GtfB primers amplify $S$. mutans gtfB gene, a previous study revealed that $g t f B$ primers yield some cross-amplification with several clinical isolates of $S$. sobrinus (defined as $S$. sobrinus species by sequencing of $16 \mathrm{SrRNA})^{10}$. To overcome this problem, the strains were also tested with $G b p B$ primers because these primers yield amplicons of predicted size in all $S$. mutans genotypes tested in a previous study $^{18}$, and do not amplify S. sobrinus sequences ${ }^{18}$. Each reaction consisted of $1 \mu \mathrm{L}$ template DNA, $10 \mu \mathrm{M}$ of each primer, $10 \mu \mathrm{M}$ of DNTP, $2.5 \mu \mathrm{L} 1 \mathrm{x}$ PCR buffer, $50 \mathrm{mM}$ $\mathrm{MgCl}_{2}$ and $5 \mathrm{U} / \mu \mathrm{L}$ Taq DNA polymerase in a total volume of $25 \mu \mathrm{L}$. The amplification reaction was performed in a thermocycler (TC-412, Techne, Duxford, Cambridge, UK) in 30 cycles as follows: denaturation $95^{\circ} \mathrm{C}$ for $30 \mathrm{~s}$, annealing at $59^{\circ} \mathrm{C}$ for $30 \mathrm{~s}$, and extension at $72^{\circ} \mathrm{C}$ for $1 \mathrm{~min}$, using $S$. mutans UA130 (kindly provided by Dr. Page W. Caufield, New York University, NY, USA) and S. sobrinus, and distilled/deionized water as positive and negative controls, respectively. The resulting amplicons were submitted to electrophoresis in 2\% agarose gels and the images were captured by a digital imaging system (Gel logic 100 Imaging System, Kodak, Tokyo, Japan).

\section{AP-PCR Reactions}

AP-PCR assays were performed with the arbitrary primers: OPA 02 (5'-TGCCGAGCTG-3') $)^{13}$, OPA 03 (5'AGTCAGCCAC-3' $)^{29}$, OPA 05 (5'-AGGGGTCTTG-3' ') ${ }^{28}$, OPA 13 (5'-CAGCACCCAC-3' $)^{28}$ and OPA 18 (5'AGGTGACCGT-3' ${ }^{29}$. The reactions were processed in 50 $\mu \mathrm{L}$ mixtures containing $1 \times$ PCR buffer, $5 \mathrm{U} / \mu \mathrm{L}$ of Taq DNA polymerase, $10 \mathrm{mM}$ DNTP, $20 \mu \mathrm{M}$ primer, $50 \mathrm{mM} \mathrm{\textrm {MgCl } _ { 2 }}$ and $2 \mu \mathrm{L}$ template DNA. Reactions were performed with the following conditions:

- OPA 02: one initial cycle of denaturation at $95^{\circ} \mathrm{C}$ for 2 min, followed by 45 cycles of $94^{\circ} \mathrm{C}$ for $30 \mathrm{~s}$ (denaturation), $36^{\circ} \mathrm{C}$ for $30 \mathrm{~s}$ (annealing) and $72^{\circ} \mathrm{C}$ for $1 \mathrm{~min}$ (extension) and a final extension at $72^{\circ} \mathrm{C}$ for $5 \mathrm{~min}$;

- OPA 03 and 18: one initial cycle of denaturation at $95^{\circ} \mathrm{C}$ for $2 \mathrm{~min}$, followed by 30 cycles of $94^{\circ} \mathrm{C}$ for $1 \mathrm{~min}$ (denaturation), $32^{\circ} \mathrm{C}$ for $1 \mathrm{~min}$ (annealing) and $72^{\circ} \mathrm{C}$ for 2 
min (extension) and a final extension at $72^{\circ} \mathrm{C}$ for $5 \mathrm{~min}$;

- OPA 05 and 13: one initial cycle of denaturation at $95^{\circ} \mathrm{C}$ for $2 \mathrm{~min}$, followed by 35 cycles of $95^{\circ} \mathrm{C}$ for $1 \mathrm{~min}$ (denaturation), $36^{\circ} \mathrm{C}$ for 2 min (annealing) and $72^{\circ} \mathrm{C}$ for 2 min (extension) and a final extension at $72^{\circ} \mathrm{C}$ for $5 \mathrm{~min}$.

The AP-PCR products were electrophoretically resolved in $1.5 \%$ agarose gels, using $S$. mutans UA130 and distilled and deionized water as positive and negative control, respectively. The gel was stained with a $5 \mu \mathrm{g} / \mathrm{mL}$ of ethidium bromide solution for $10 \mathrm{~min}$, and their images were captured by a digital imaging system (Gel logic 100 Imaging System, Kodak, Tokyo, Japan). A 1-Kbp DNA ladder served as a molecular-size marker in the gel. The amplicon profiles (amplitypes) of the same volunteer were always resolved side-by-side in the same gel for visual comparisons ${ }^{1,11,25}$. Isolates were considered as having the same genotypic identity when presented identical AP-PCR product-size profiles. Any repeatable difference regarding the strong bands was considered discriminatory. The genotypes found were analyzed descriptively and their proportion, in relation to the number of colonies isolated in each sample and condition, was calculated. Also, the number of bands from each genotype amplified by each of the arbitrary primers was counted and the mean value was calculated. were identified as $S$. mutans in the PCR reactions with specific primers. A total of 14 distinct genotypes were identified among the 88 isolates tested. Most volunteers (9 out of 11) carried only one genotype (Table 1$)$. The exceptions were volunteer 8 , who harbored 3 genotypes identified with all tested arbitrary primers (Figure 1), and volunteer 11, who presented 2 genotypes when evaluated using the following primers: OPA 02, 03, 05 and 13. Using primer OPA 18 , volunteer 11 presented only 1 genotype in saliva. Considering the proportions of genotypes in relation to the total number of isolates, in volunteer 8 , the predominant genotype was "H" $(75 \%)$ and the others, "I" and "J", represented $12.5 \%$ each one of the 8 isolates of this volunteer. For volunteer 11, the predominant genotype was "M" $(87.5 \%)$ and the genotype "N" represented $12.5 \%$. In addition, the genotypes were distinct among all volunteers. Table 1 also presents the number of bands produced after the AP-PCR reaction with each one of the arbitrary primers tested. The amplification with OPA 02 primer resulted in a higher number of bands (mean of 11.9), in relation to the other primers. OPA 03 primer presented around 9.7 bands and the other primers between 8.6 and 8 bands.

\section{RESULTS}

A total of 88 representative colonies of $S$. mutans were isolated from saliva, being 8 from each volunteer. All isolates

TABLE 1- Genotypic diversity of $S$. mutans (\%) in stimulated saliva and number of bands produced by each primer

\begin{tabular}{|c|c|c|c|c|c|c|}
\hline \multirow[t]{2}{*}{ Volunteer } & \multirow{2}{*}{$\begin{array}{c}\text { Genotype } \\
(\%)^{\star}\end{array}$} & \multicolumn{5}{|c|}{ Number of bands } \\
\hline & & OPA 02 & OPA 03 & OPA 05 & OPA 13 & OPA 18 \\
\hline 1 & $A(100)$ & 9 & 11 & 8 & 8 & 7 \\
\hline 2 & B (100) & 10 & 9 & 7 & 8 & 7 \\
\hline 3 & C (100) & 11 & 11 & 6 & 9 & 9 \\
\hline 4 & D (100) & 14 & 8 & 11 & 11 & 9 \\
\hline 5 & $E(100)$ & 13 & 10 & 8 & 10 & 9 \\
\hline 6 & $F(100)$ & 15 & 10 & 10 & 11 & 8 \\
\hline \multirow[t]{2}{*}{7} & G (100) & 13 & 9 & 8 & 9 & 8 \\
\hline & $\mathrm{H}(75)$ & & & & & \\
\hline \multirow[t]{2}{*}{8} & I (12.5) & 11 & 11 & 7 & 8 & 7 \\
\hline & $\mathrm{J}(12.5)$ & & & & & \\
\hline 9 & K (100) & 13 & 10 & 7 & 7 & 9 \\
\hline 10 & $L(100)$ & 11 & 10 & 8 & 7 & 9 \\
\hline \multirow[t]{2}{*}{$11^{* *}$} & $M(87.5)$ & & & & & \\
\hline & $\mathrm{N}(12.5)$ & 11 & 8 & 8 & 7 & 10 \\
\hline $\begin{array}{l}\text { Mean number } \\
\text { of bands }\end{array}$ & & 11.9 & 9.7 & 8.0 & 8.6 & 8.6 \\
\hline
\end{tabular}

* The proportion (\%) of the genotypes in relation to the number of colonies isolated in each condition is represented within the parenthesis. ${ }^{\star \star}$ The genotypes $\mathrm{M}$ and $\mathrm{N}$ were identified by all primers, except for OPA 18. 

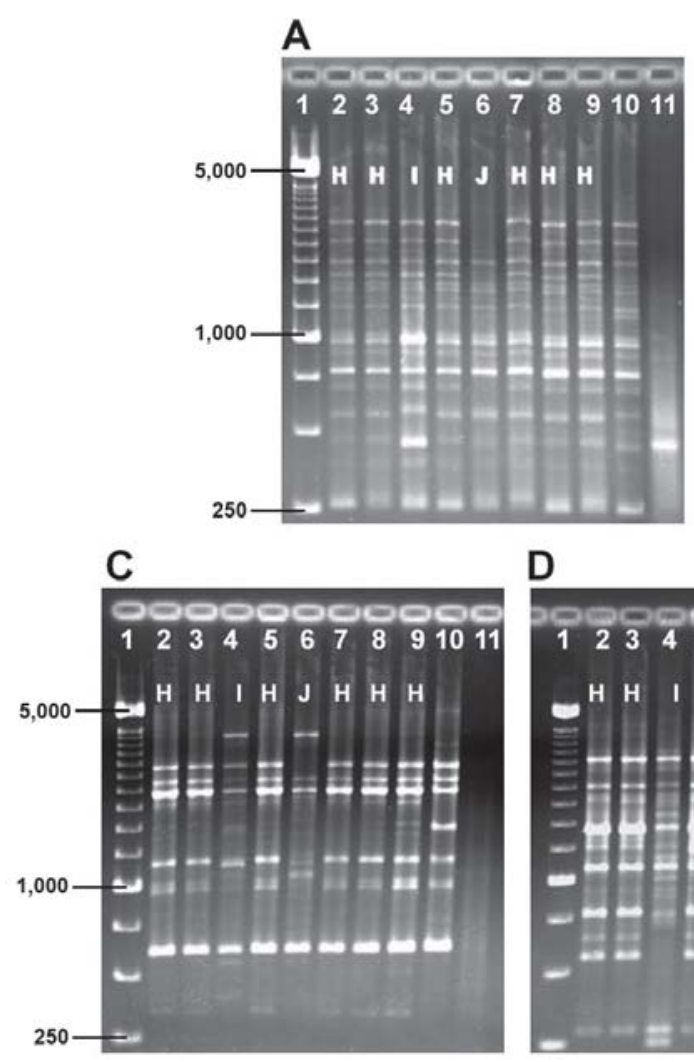

B

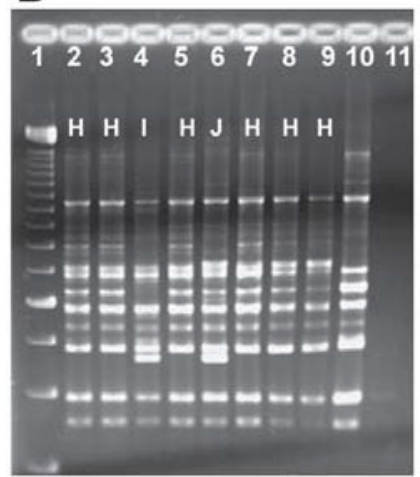

E

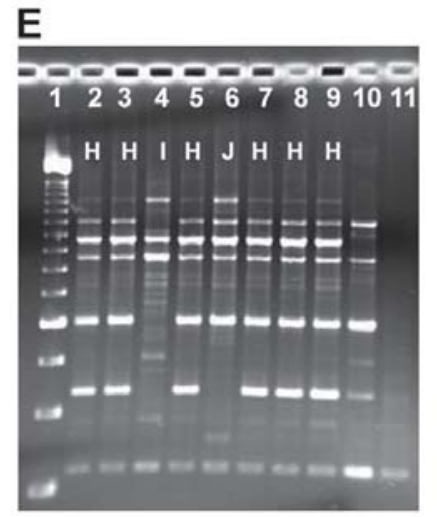

FIGURE 1- Representative AP-PCR profiles (amplitypes) identified among $S$. mutans strains isolated from volunteer 8 , with OPA 02 (A), OPA 03 (B), OPA 05 (C), OPA 13 (D) e OPA 18 (E). Lane 1: 250-bp DNA ladder; lanes 2 to 9: S. mutans amplitypes; Lane 10: AP-PCR profile of the control S. mutans strain UA 130; lane 12: negative control (water)

\section{DISCUSSION}

It is well known that the oral cavity harbors distinct genotypes of $S$. mutans $^{9,12,18,20,27,28}$. In the present study, only one genotype was found in the saliva of 9 out of 11 volunteers (Table 1). This agrees with the findings of previous studies in saliva or dental biofilm samples of children ${ }^{9,12,18,20,27,28}$ and adult subjects ${ }^{1,21}$. This low genotypic diversity could be related to the fact that other genotypes might be present in saliva in a proportion below to the detection limit of the microbiological method used ${ }^{26}$. Also, certain genotypes present in the oral cavity could become permanently established, while other genotypes, due to their reduced ability of interacting with the host, form a transient population ${ }^{21}$. Despite this low genotypic diversity found in the present study, saliva samples harbor those genotypes present at higher proportions in dental biofilms ${ }^{1,12}$. In the present study, although distinct genotypes were identified by all primers tested, the OPA 02 showed the best results, considering the number of bands produced by reaction (Table 1). These data are in agreement with the study of $\mathrm{Li}$ and Caufield ${ }^{13}$ (1998).

Despite the lower number of bands yielded in reactions with OPA 03, when compared to primer OPA 02, primer OPA 03 allowed an efficient differentiation of genotypes. This result is in contrast with those of $\mathrm{Li}$ and Caufield ${ }^{13}$ (1998), who found that OPA 03 presented a lower discriminatory capacity than OPA 02 . In addition, OPA 05 ,
13 and 18 showed a smaller number of bands than OPA 02 and OPA 03 (Table 1).

The reduced number of bands might decrease the differentiation among genotypes, since just one genotype was identified by OPA 18 in volunteer 11, compared to the other two genotypes identified with the other primers (Table 1). In addition, although OPA 05 produced fewer bands than OPA 02 and 03, which might make difficult the differentiation of the genotypes, it seems that this characteristic did not impair the identification and differentiation of the genotypes in the samples analyzed. Because of this finding, considering the results of the present study, an association between OPA 02 and OPA 03 or OPA 02 and OPA 05 may be useful in the identification of genotypic diversity. Nevertheless, further studies should evaluate a larger number of volunteers and different samples, such as biofilm, which present a higher diversity, using different primers.

\section{CONCLUSIONS}

In conclusion, the results of the present study suggest that primers OPA 02, 03, 05 and 13 were suitable for genotypic identification of $S$. mutans isolates of saliva from adult volunteers. 


\section{ACKNOWLEDGMENTS}

The authors would like to thank the volunteers for their valuable participation, and FAPESP (06/02308-9), from which the second author received a scholarship during her undergraduation course in Dentistry at FOP-UNICAMP, working under direct supervision of the third author.

\section{REFERENCES}

1- Arthur RA, Tabchoury CPM, Mattos-Graner RO, Del Bel Cury AA, Leme AFP, Vale GC, et al. Genotypic diversity of $S$. mutans in dental biofilm formed in situ under sugar stress exposure. Braz Dent J. 2007; 18:185-91

2- Bowen W, Amsbaugh SM, Monell-Torrens S, Brunelle J, KuzmiakJones H, Cole MF. A method to assess cariogenic potential of foodstuff. J Am Dent Assoc. 1980;14:24-31.

3- Cury JA, Rebelo MAB, Del Bel Cury AA, Derbyshire MTVC, Tabchoury CPM. Biochemical composition and cariogenicity of dental plaque formed in the presence of sucrose or glucose and fructose. Caries Res. 2000;34:491-7.

4- Cury JA, Francisco SB, Del Bel Cury AA, Tabchoury CPM. In situ study of sucrose exposure, mutans streptococci in dental plaque and dental caries. Braz Dent J. 2001;12:101-4

5- Dibdin GH, Shellis RP. Physical and biochemical studies of Streptococcus mutans sediments suggest new factors linking the cariogenicity of plaque with its extracellular polysaccharide content. J Dent Res. 1988;67:890-5.

6- Grönroos L, Alaluusua S. Site-specific oral colonization of mutans streptococci detected by arbitrarily primed PCR fingerprinting. Caries Res. 2000;34:474-80.

7- Hames-Kocabas EE, Uçar F, Ersin NK, Uzel A., Alpöz AR. Colonization and vertical transmission of Streptococcus mutans in Turkish children. Microbiol Res. 2008;163:168-72.

8- Huang X, Liu T, Yang J, Chen Z, Liu J. Evaluation of cariogenic potentia of Streptococcus mutans isolated from caries-free and -active persons: abilities to synthesize water-soluble and -insoluble glucans. Hua Xi Kou Qiang Yi Xue Za Zhi. 2000;18:419-21.

9- Klein MI, Florio FM, Pereira AC, Hofling JF, Gonçalves RB. Longitudinal study of transmission, diversity and stability of Streptococcus mutans and Streptoccocus sobrinus genotypes in Brazilian nursery children. J Clin Microbiol. 2004;42:4620-6.

10- Klein MI, Bang S, Flório FM, Höfling JF, Gonçalves RB, Smith DJ, et al. Genetic diversity of competence gene loci in clinical genotypes of Streptococcus mutans. J Clin Microbiol. 2006;44:3015-20.

11- Kreulen CM, Soet HJ, Hogeveen R, Veerkamp JSJ. Streptococcus mutans in children using nursing bottles. ASDC J Dent Child. 1997;64:107-11.

12- Lembo FL, Longo PL, Ota-Tsuzuki C, Rodrigues CR, Mayer MP. Genotypic and phenotypic analysis of Streptococcus mutans form different oral cavity sites of caries-free and caries-active children. Oral Microbiol Immunol. 2007;22:313-9.

13- Li Y, Caufield PW. Arbitrarily primed polymerase chain reaction fingerprinting for the genotypic identification of mutans streptococci from humans. Oral Microbiol Immunol. 1998;13:17-22.
14- Li Y, Caufield PW, Redmo Emanuelsson I, Thornqvist E. Differentiation of Streptococcus mutans and Streptococcus sobrinus via genotypic and phenotypic profiles from three different populations. Oral Microbiol Immunol. 2001;16:16-23.

15- Loesche WJ. Role of Streptococcus mutans in human dental decay. Microbiol Rev. 1986;50:353-80.

16- Marsh PD. Are dental diseases examples of ecological catastrophes? Microbiology. 2003;149:279-94.

17- Mattos-Graner RO, Smith DJ, King WF, Mayer MPA. Water-insoluble glucan synthesis by mutans streptococcal strains correlates with caries incidence in 12- to 30-month-old children. J Dent Res. 2000;79:1371-7.

18- Mattos-Graner RO, Jin S, King WF, Chen T, Smith DJ, Duncan MJ Cloning of the Streptococcus mutans gene encoding glucan binding protein $\mathrm{B}$ and analysis of genetic diversity and protein production in clinical isolates. Infect Immun. 2001;69:6931-41.

19- Mattos-Graner RO, Napimoga MH, Fukushima K, Duncan MJ, Smith DJ. Comparative analysis of Gtf isozyme production and diversity in isolates of Streptococcus mutans with different biofilm growth phenotypes. J Clin Microbiol. 2004;42:4586-92.

20- Napimoga MH, Kamiya RU, Rosa RT, Rosa EA, Hofling JF, MattosGraner RO, et al. Genotypic diversity and virulence traits of Streptococcus mutans in caries-free and caries-active individuals. J Med Microbiol. 2004:53:697-703

21- Nie M, Fan M, Bian Z. Transmission of mutans streptococci in adults within a Chinese population. Caries Res. 2002;36:161-6.

22- Nobre dos Santos M, Melo dos Santos L, Francisco SB, Cury JA. Relationship among dental plaque composition, daily sugar exposure and caries in the primary dentition. Caries Res. 2002;36:347-52.

23- Nogueira RD, Alves AC, Napimoga MH, Smith DJ, Mattos-Graner RO. Characterization of salivary immunoglobulin A responses in children heavily exposed to the oral bacterium Streptococcus mutans: influence of specific antigen recognition in infection. Infect Immun. 2005;73:567584.

24- Oho T, Yamashita Y, Shimazaki Y, Kushiyama M, Koga T. Simple and rapid detection of Streptococcus mutans and Streptococcus sobrinus in human saliva by polymerase chain reaction. Oral Microbiol Immunol. 2000;15:258-62.

25- Redmo-Emanuelsson IM, Thornqvist E. Distribution of mutans streptococci in families: a longitudinal study. Acta Odontol Scand. 2001;59:93-8.

26- Redmo-Emanuelsson IM, Carlsson P, Hamberg K, Bratthall D. Tracing genotypes of mutans streptococci on tooth sites by random amplified polymorphic DNA (RAPD) analysis. Oral Microbiol Immunol. $2003 ; 18: 24-9$

27- Saarela M, Alaluusua S, Tsutomu T, Asikainen S. Genetic diversity within isolates of mutans streptococci recognized by an rRNA gene probe. J Clin Microbiol. 1993;31:584-7.

28- Saarela M, Hannula J, Mättö J, Asikainen S, Alaluusua S. Typing of mutans streptococci by arbitrarily primed polymerase chain reaction. Arch Oral Biol. 1996;41:821-6.

29- Truong TL, Menard C, Mouton C, Trahan L. Identification of mutans and other oral streptococci by random amplified polymorphic DNA analysis. J Med Microbiol. 2000;49:63-71. 